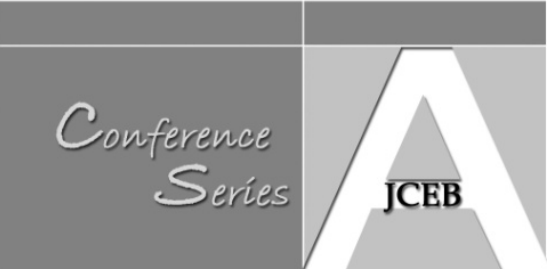

\title{
Work Integrated Learning and the Case for a "Student-Industry Network" in Undergraduate Construction Management Programs
}

Perry Forsythe (University of Technology Sydney, Australia)

\begin{abstract}
The term "work ready graduates" is commonly used by Universities to describe students who have been well prepared and who can seamlessly enter professional practice. It is an ideal that is simpler said than achieved in reality. Students in construction management often work and study concurrently but this is often undertaken in an ad hoc way that does not derive the benefits of the potential synergy between the two. The paper explores the need to create such synergy by operationalising Work Integrated Learning concepts and the issues and conditions involved in implementing at the studywork interface for construction management students. The extant literature is used to build the case and identify relevant issues that need to be addressed in the context of contemporary higher education thinking. Research findings are presented from the perspective of the university sector, the student and the industry. Based on findings and insights from these stakeholders, the paper proposes a means of enabling Work Integrated Learning via a structured student-industry network. The brief for such a network is introduced with a view to real world application.
\end{abstract}

Keywords: Work Integrated Learning, Construction Management, Reflective Learning

\section{Introduction}

In the Australian context, a degree of research has been undertaken concerning the studywork interface for undergraduate construction management students, notably efforts by Lingard (2007), Lingard (2005) and Lingard et al. (2003). This paper adds to this body of working by taking a more operational perspective about how Universities can functionally address issues at the study-work interface. It is an important issue as students often undertake work and study concurrently, and insufficient is being done to create synergy between these overlapping roles.

To place the scale of the potential overlap into perspective, Forsythe and Zou (2006) studied students across an undergraduate construction management program at a Sydney based university and found that $62 \%$ were undertaking paid work and $41 \%$ were doing so in their chosen discipline. The work commitment increased in the latter years of study whereby 3rd year students were averaging 26 hours work per week whilst concurrently undertaking full-time study, and 4th year students were averaging 38 hour per weeks. Even so, there is evidence from the peak body, Universities Australia (2008a), that most students find work independently and this is often undertaken in an ad hoc way that doesn't necessarily synergise with University learning outcomes.

The aim of this paper is therefore to explore the need for University Construction Management Programs to nurture and create improved synergy between the study-work interface for students. To this end, the paper uses the extant literature to identify relevant issues that need to be addressed in the context of contemporary higher education thinking. The paper also proposes the treatment of such issues by way of an enabling mechanism, namely a structured "Student-Industry Network". 


\section{Operationalising Learning Concepts and Theory}

The main learning concepts being operationalised in meeting the above aims primarily concern Work Integrated Learning (WIL). Peach and Gamble's (2011) identifying the following commonly agreed features of WIL including (Pp 174-175):

- being based on identified industry needs and expectations of graduates and employees (for example, professional accreditation), which are integrated into the curriculum;

- inclusion of the work component as part of the overall curriculum design;

- involvement of industry partners who, in addition to providing advice on curriculum design, also provide workplaces for students to gain experience; and

- a formal system which supports students and provides a framework for organising and assessing student work and experience.

WIL is perhaps best seen in the context of supplementing existing methods of learning by creating the opportunity for a more self-driven, reflective approach. Interest in it is said to come from a reaction against an overly didactic, teacher controlled and discipline-constrained transmission of knowledge (Andresen et al. 1995). WIL draws on learning theories such as experiential-based learning, immersive learning and transformative learning (Andresen et al. 1995; Mezirow 1995).

In the context of transformative learning, Mezirow (1995) expands on reflection as enabling people to correct distortions in their beliefs and errors in problem-solving. He defines critical reflection as challenging the validity of presuppositions in prior learning. For instance, students can compare, confirm or adapt their University learning with what they find in their workplace experiences. From this, they can create new "meaning perspectives" which enable higher level interpretation of the structure of their assumptions i.e. new experiences are assimilated and transformed from past experiences (Mezirow 1995). These qualities are quite distinct from a didactic andragogy 1 and are rooted in the use of life experiences, thus making it a student-centred approach to learning (Andresen et al. 1995; Ball 2008; Litchfield et al. 2010). Even so, this means students must be encouraged take a degree of control over their performance as learners rather than simply turning up for class and doing whatever they are told to do (Harvey 2000).

A key objective of WIL is to consolidate and complement academic learning while integrating aspects of personal career awareness and development (Smith et al. 2009). With regard to this, research has shown that experiential learning set within an appropriate professional context can support and assist learning at university by providing an applied understanding of the theory and principles taught at university (Stinson 1990; Precision Consultancy 2007; Universities Australia 2008a). It also works in reverse, in so far as requiring students to apply what they have learnt at University to their work setting (Peach and Gamble 2011). In a more general sense, WIL aims to not only legitimize learning content but engage student motivation for learning (Litchfield et al. 2010).

\footnotetext{
1 Andragogy refers to helping adults learn and is therefore distinct from pedagogy which focuses more on the teaching of children.
}

Forsythe, P. (2012) 'Work integrated learning and the case for a "student-industry network" in undergraduate construction management programs', Australasian Journal of Construction Economics and Building, Conference Series, 12 (1) $1-11$ 
Given the above, it is relevant that Forsythe and Zou (2006) found that construction management students who worked while studying, more positively agreed that their studies had assisted their ability to be a team member and their confidence in tackling unfamiliar problems than those who did not work. They were also more satisfied with the overall quality of their course than those who did not work. Even so, Knight and Yorke (2004) found that work experience without adequate support from higher education providers did little for student learning. Further, O’Shea (2009) suggests that early in a degree program it is best to let students focus on classroom-based scenarios but in later years there should be increasing exposure to more demanding activities and in workplace involvement. Clearly, such factors need to be taken into account in order to maximize WIL and in the design of enabling mechanisms such as the proposed Student Industry Network.

\section{The University Sector's Perspective of the Study-Work Interface}

The previous discussion recognises that learning continues to take place in a variety of environments (including overlapping environments) and over an extended period of time. This is broadly consistent with the current focus of the higher education sector in Australia which advocates the philosophy of lifelong learning. For instance, Bradley et al (2008) emphasise that "There is a need to turn the rhetoric of lifelong learning into a reality, a need to take account of what is happening to those already in the workforce and develop a well-coordinated, systematic approach to addressing these issues and the numbers gaining qualifications.” (p. x). Similarly, the Federal Government's policy “Transforming Australia's Higher Education System" (2009) acknowledges its support for the "Bradley report" and states that higher education should be able to "engage effectively with other education and training sectors to provide a continuum of high quality learning opportunities throughout an individual's life” (p. 7).

In the context of such broad based policy is the need to deliver day to day implementation. The emphasis in this paper is on the overlap and ultimately the change over from university study to the professional work place. In this context, peak bodies such as Universities Australia (2008a) clearly support the benefits of work based internship schemes and they have garnered support for this from industry as well2. Even so, authors such as Peach and Gamble (2011) point to on-going tensions concerning the beliefs and values of industry, the community and students, about the kinds of educational purposes that universities should serve. At its core, they identify that professional and business communities want job-ready graduates who have the requisite competencies to undertake work immediately, but this is not always feasible from the University side of the equation, as there is less emphasis on work competencies and greater emphasis on attributes such as learning how to think and solve problems. Such tensions are not new. For instance, Litchfield et al (2010) cite a variety of reports spanning a 20 year period stating the need for universities to produce graduates that are more ready for professional employment. It is also argued that in current times, the traditional focus of the university curriculum can no longer focus purely on the professional and disciplinary body-of knowledge because this alone is no

\footnotetext{
${ }^{2}$ Note: A government internship scheme now exists as set up at the Australian National University, (refer http://anip.anu.edu.au/) but this is currently only a fledgling scheme capable of handling a limited number of students place predominantly within government settings
}

Forsythe, P. (2012) "Work integrated learning and the case for a "student-industry network" in undergraduate construction management programs', Australasian Journal of Construction Economics and Building, Conference Series, 12 (1) 1-11 
longer sufficient to meet various stakeholder needs (Litchfield et al. 2008). Along a similar vein, authors such as Harvey (2000) point out that for some, the intention to forge a relationship between academia and employment may be seen as "anti-intellectualism" and eroding academic freedom. It may also be seen as making higher education subservient to training graduates for jobs rather than improving their minds. However Harvey (2000) also makes the mediating point that the two can work in a synergistic way that need not erode the traditional intent of university education. Here (Harvey 2000, p4) states that the "Higher education-employment interface should not be seen as an 'add-on' to academic study. Conversely, the 'employability' of graduates should not be seen as the primary focus of higher education. Rather, employability is a subset of, and fundamentally contingent on, transformative lifelong learning." - a view that is seemingly consistent with the previous discussion on higher education policy in Australia.

Despite such intentions, Universities are now required to be more entrepreneurial than ever before. Universities Australia (2008b) make the point that universities have independently grown their private income sources more than any other OECD country in the past decade or more, but core funding has not kept pace with costs. In the near future the Government will also abolish the existing system for full-fee domestic undergraduate places in public universities (Universities Australia 2008b). It is clear that the number of places offered by individual universities and the implicated market demand issues will become the subject of open competition.

Peach and Gamble (2011) point to related entrepreneurship pressures that have arisen over an extended period of time including: the massification of higher education; the introduction of a user-pays system; the growing emphasis on completing degrees in shorter periods of time and the pressure to continually demonstrate the relevance of programs, whilst also being responsive to the needs of fee-paying students. They believe that a consequence of all this has seen an increased interest in WIL. In adding to their line of logic, it may therefore be the case in the future that University Construction Management programs use WIL as an effective and efficient means of developing competitive advantage in an otherwise cluttered market place.

The above discussion paints a picture that supports WIL but one that leaves questions concerning how to appropriately resource and implement it. Time invested in WIL has proven to be even more resource-intensive than other forms of learning (Peach and Gamble 2011). Further, unlike professions such as nursing, teaching, law, science and psychology (Universities Australia 2008a), there is currently little development of a structured studywork interface in construction management degree programs. This is the case even though many programs still retain minimum work experience or employability measures - as required by the likes of accrediting industry associations. As such, efforts are often made by construction management programs to record students' work experience hours, but a structured means of linking this to University learning outcomes is generally less evident.

\section{Construction Management Programs and Curriculum Design Issues}

In addition to the macro level debate above, there is the need to consider how the likes of WIL and related enabling mechanism such as a Student-Industry Network can be integrated in a way that harmoniously enhances overall curriculum design. For instance, good design is

Forsythe, P. (2012) 'Work integrated learning and the case for a "student-industry network" in undergraduate construction management programs', Australasian Journal of Construction Economics and Building, Conference Series, $12(1) 1-11$ 
said to start with a set of values and beliefs about what students should learn via a mix of both external agencies and internal deliberations (Macquarie University 2012). It must also be aligned with the achievement of the University's graduate capabilities framework (Macquarie University 2012). For instance the author's own University - the University of Technology Sydney - has a dedicated "Model of Learning" that drives overarching curriculum design issues (University of Technology Sydney 2012). Among three distinctive and interrelated dimensions of this model, the main one of relevance to this paper concerns "integrated exposure (of students) to professional practice through dynamic and multifaceted modes of practice-oriented education” (University of Technology Sydney 2012) - hence supporting the relevance of WIL and the establishment of an enabling Student-Industry Network.

In terms of undergraduate capabilities there have been moves recently to rationalize requirements across the Construction Management discipline i.e. to seek a degree of consistency regarding student capabilities. A recently completed project concerning Learning and Teaching Academic Standards in Building and Construction developed a set of threshold learning outcomes (TLOs) via extensive consultation with industry, professional bodies, academics, students and recent graduates. Six TLO categories were identified, including: knowledge, judgement, self-development, communication, innovation, and engagement. Here, the concept of WIL is highly consistent with the three of the six TLOs which are provided in full definition below (Newton 2011):

- self-development i.e. where students critically and creatively reflect on personal behaviours and capabilities in the context of entry to professional practice,

- judgement i.e. Where students identify and resolve typical building challenges with limited guidance employing appropriate evidence-based problem-solving and decision-making methodologies

- engagement i.e. where students demonstrate an integrated understanding of both the theory and practice of building and construction based on experience

As such, it would seem there is a strong argument for considering WIL and though the above discussion has an orientation towards the situation at UTS, it would seem that uptake of the abovementioned TLOs would create reason for considering the implementation of WIL at a broader level as well.

\section{The Student's Perspective of the Study-Work Interface}

Students' interests are obviously at the core of this paper and though their needs are often debated at policy level by others, research into student specific perspectives are useful in understanding the best pathway forward. At an overarching level, students expect their studies to provide them with the ability to be employed in their chosen occupation and according to an analysis of open-ended comments from over 94,000 student from 14 Australian universities, students want a 'total experience of university not just what happens in the traditional classroom’ (Scott 2008).

In building on such holistic statements, research suggests the need to deal with satisfaction differently as students pass through their construction management studies. For

Forsythe, P. (2012) 'Work integrated learning and the case for a "student-industry network" in undergraduate construction management programs', Australasian Journal of Construction Economics and Building, Conference Series, 12 (1) $1-11$ 
instance, Pate (1993) identifies student satisfaction under three perspectives including psychological-wellness, consumer satisfaction and job satisfaction whereby the latter can depend on outcomes such as being recruited by progressive, exciting and well-paying employers. Adding further insight, Peach and Gamble (2011, p. 171) make the point that even though students have strong expectations about where education will take them, they may still have an underdeveloped understanding of the requirements of their selected profession. It is apparent that WIL may allow them the ability to test and develop their areas of interest and that the likes of a structured Student Industry Network could offer a viable means for facilitating this to take place.

Even so, the transition process in moving from study to work is often characterized as being highly stressful for students. Davis's study (2010) found that newly hired graduates thought that employers were not doing enough to assist them in their transition process and that there was a need for specific assistance in becoming socialized into the organization including the need for senior level mentors from within. Davis (2010) also makes the point that even though employers may have the expectation that recent graduates are mature and ready to handle their new positions, students are still developing - especially in things like the challenges they face in their personal lives during the period of transition into the workplace.

It is perhaps notable that in the context of construction project management, the situation may be particularly tough for students because as mentioned earlier in the paper, it is likely that many will have significant study and work commitments (Forsyth and Zou 2006), thus highlighting the time pressure they are under to perform.

Pressure also stems from other quarters as well. For instance Harvey (2000) points out that more people now hold university degrees than in previous times and so the supply of highly educated labour has increased but demand may not keep up at the same rate. In such instances there is clearly added competitive pressure for students to have a presence in the chosen workforce, whilst studying, to improve their competitiveness once they leave University and become fully committed to their profession.

Given the above, it would seem that an ad hoc approach to the study-work overlap could disastrously lead to unnecessary student pressure and perhaps even burnout. Hence, the prospect of study and work occurring in a structured way such as the proposed Student Industry Network, could provide a more safe and controlled means for this to take place.

\section{The Industry Perspective of the Study-Work Interface}

It has been said that many employers now recognise that a qualified and well-trained workforce is perhaps the most critical factor to sustained growth and competitiveness (Cheney 2001). According to Dreher and Daugherty (2001), top-performing companies must therefore be better than their competitors at recruiting and retaining top talent.

Students and recent graduates represent the youngest group of employees and so organisations must work at capturing, retaining, motivating and developing these people (Kyles 2006). In building on this, Davis (2010, p.19) makes the point that business employers are now more aware that educating future employees is a shared responsibility between corporations and educators, and that this often involves developing partnerships.

Forsythe, P. (2012) 'Work integrated learning and the case for a "student-industry network" in undergraduate construction management programs', Australasian Journal of Construction Economics and Building, Conference Series, $12(1) 1-11$ 
Even so, research conducted by the Alliance for Management Education Task Force (2006) found that senior business leaders in the US were not necessarily happy with the capability of students to adapt to change, work in teams and apply their analytical abilities to solving real world work place problems. They acknowledged the symbiotic nature of the relationship between education and business success but business leaders expressed that they were unlikely to enter a partnership with Universities unless they believed it would provide added value to their organisations (Association to Advance Collegiate Schools of Business 2006, pp. 10-11).

Therefore having a structure in place to accommodate these sentiments is clearly important to business leaders. Common approaches to engagement between Universities and business include scholarships, internships and student prizes. Of note, research shows that vehicles such as Internship programs are useful and can readily convert to full time positions (Universities Australia 2008a; Sasser 2009). In addition, the National Association of Colleges report that US employers commonly use formal programs to test out potential hires and that just over 90 percent of new recruits at companies with formal internships program were still employed after one year, but for other organisations that did not have a formal program, only 60 percent of new recruits were retained (Sasser 2009). Prizes and awards can represent a more common mode of engagement between universities and business but in general, this vehicle represents a less defined means for students to obtain work experience with the sponsoring organizations. Based on experiences at the University of Technology Sydney, there is a significant number of such awards and prizes and perhaps there is potential that these could be adapted to yield stronger potential for workplace experience.

Despite the obvious benefits of these mechanisms, it is perhaps unrealistic to have such pathways available for all the students in a degree program. It is unlikely there will be enough to go round. Here, Peach and Gamble (2011) and Edwards (2007) assert that lower achieving students often benefit most from the developmental opportunities afforded by WIL and so they need to be included as well - not just high achievers. Further to this, the author's own personal experience has been that not all businesses want high achieving students, instead some simply want "honest, hard workers".

As such, it would seem that equity and competitive issues need to be resolved in terms of ensuring a good fit with employer's needs and not purely on academic achievement. It would also seem that there is real benefit in undertaking a more systematic approach that is not purely centred on annual awards, prizes scholarships and internships but one that allows opportunity at a broader level. Here, authors such as Precision consultancy (2007) propose a database to assist work experience for students. It is apparent that the benefit of this approach is its continuous availability for meeting that student industry needs.

\section{Conclusion - the Conceptualisation of a Student-Industry Network}

Given the previous discussion, the view is taken that there will indeed be increasing pressure to synergise the study-work interface. A good way of acting on this, that is consistent with higher education policy and with student driven learning in mind (such as reflective learning) is by adopting WIL. This must support rather than dominate existing forms of University learning. As alluded to earlier in the paper it is proposed that the establishment of a structured Student-Industry Network (SIN) would be very useful in enabling the

Forsythe, P. (2012) 'Work integrated learning and the case for a "student-industry network" in undergraduate construction management programs', Australasian Journal of Construction Economics and Building, Conference Series, $12(1) 1-11$ 
implementation of WIL. With regard to this, a partnering approach between Universities and industry seems to offer the best way forward - an idea supported by others including Universities Australia (2008a), Orrell (2004) and Patrick (2008). Here, the conceptualization of SIN must aim to serve overarching WIL objectives whilst acknowledging and assisting the objectives of students and industry members as well. Given that the implementation of WIL may be resource intensive - coupled with the apparent lack of core University funding for such initiatives - partnership arrangements may well need to involve financial contribution by industry to make SIN viable. For similar reasons, SIN needs to be scalable according to the availability of funds and resources. Here, it is thought that the approach should first aim to create a mechanism for students and industry to engage about work experience opportunities, then gradually upgrade the model to refine WIL outcomes i.e. based on experience gained during implementation.

Arguably, the most viable means for this first step to take place is by the development of a web database. It could provide a structured centerpiece positioned between student and industry members i.e. for students and industry members to present their respective profiles, to be able to let respective parties filter search each other according to selected criteria, and to allow interested parties to get in touch with each other. The database would offer continuous access and opportunities for work placements and could also be used to work synergistically with more periodic mechanisms such as awards, prizes, scholarships and internships. Further, the database could be supplemented by other forms of interaction such as functions between students and industry whereby a personality can be added to the online information. Of note, the primary purpose of the database would be to reduce the current reliance of ad hoc employment and work placement i.e. by replacing it with a more efficient, controlled and measurable approach that aims to track work experience, reduce unnecessary study-work pressures on students and record WIL outcomes. In this context, SIN must still be geared to allow for different types of work placement experiences in order to cater for the full cohort of students and so this must include options beginning with basic and temporary work experience through to more competitive options including internships, scholarships and traditional employment. Further to these core features there are a number of more detailed practical and philosophical issues to consider, for instance:

A potential problem exists where students enter high level work commitments to early in their university studies - hence their studies suffer. Students also have relatively little knowledge of key principles early in their degree programs and may therefore not be able to appropriately relate their work place learning with their University learning. As such, it is thought that students should attain a minimum number of credit points in their degree before being allowed to participate in SIN

Industry members should be asked as part of their SIN membership to adopt a moral commitment regarding the welfare of the students they take on i.e. work should be set in a way that is mindful that the student is concurrently studying and working and that the overlap between these two roles is also designed to achieve WIL outcomes

In the work place, senior level mentors within the companies should be linked to students to ensure that they assimilate appropriately into the workplace and that a balance remains between the student's work and study commitments.

There is the question of how many and what sort of industry members to seek in SIN. Here, quality seems better than quantity. This can be defined in terms of strong industry members

Forsythe, P. (2012) 'Work integrated learning and the case for a "student-industry network" in undergraduate construction management programs', Australasian Journal of Construction Economics and Building, Conference Series, $12(1) 1-11$ 
who can offer diverse work experiences and have respect for the previously stated student and university needs. In addition, members should align with the strategic direction of the School or program involved. Those that can take on multiple students provide additional benefits mainly concerning the administration and management of SIN.

SIN involves significant privacy, probity and legal issues for students, the University and industry alike. Care must be taken to develop SIN in a way that transparently protects these interests and undertakes an appropriate duty of care.

An interesting and less obvious aspect relating to the SIN concept is simply the ability for academics to have a reason to converse and have a working relationship with industry over a common area of interest i.e. students. Here, research is typically a key performance indicator for most academics but it is not necessarily easy for academics to develop research relationships with industry. SIN can be used as the basis for extending an initial relationship into a research oriented one as well.

The previous points have been collectively taken into account by the author who has embarked on the development of a prototypical Student-Industry Network. Its progress will be reported more fully after trial implementation phase where appropriate testing an evaluation will be undertaken.

\section{References}

Andresen, L., Boud, D. Cohen, R. (1995). 'Experience-based learning: Contemporary issues', in Understanding adult education and training, ed. G. Foley., Allen \& Unwin, Sydney, pp. 225-239.

Association to Advance Collegiate Schools of Business (2006). Business and Business Schools: A Partnership for the Future, Association to Advance Collegiate Schools of Business. Tampa, Florida.

Australian Government (2009). Transforming Australia's Higher Education System, Commonwealth of Australia, Canberra.

Ball, L. (2008). Bold resourcefulness: redefining employability and entrepreneurial learning report, University of the Arts London.

Bradley, D., Noonan, P. Nugent, H. Scales, B. (2008). Review of Australian Higher Education, Final Report, Canberra.

Cheney, S. (2001). Keeping Competitive: Hiring, Training, and Retaining Qualified Workers, Report, Chamber of Commerce of the United States, Washington, retrieved from http://www.eric.ed.gov/PDFS/ED467592.pdf , <February 27 2012)

Davis, G. J. (2010). The perceptions of recent business graduates of the transition experience from the collegiate environment to the work environment, Doctoral thesis, University of North Florida, Florida.

Dreher, G. and Dougherty, T. W. (2001). Human resource strategy: A behavioral perspective for the general manager, McGraw-Hill, New York.

Forsythe, P. (2012) 'Work integrated learning and the case for a "student-industry network" in undergraduate construction management programs', Australasian Journal of Construction Economics and Building, Conference Series, 12 (1) $1-11$ 
Edwards, D. (2007). 'Improving student achievement through an industry placement.' Proc., International Conference on Engineering Education, September 3 - 7, 2007, Coimbra, Portugal.

Forsythe, P. and Zou, P. (2006). 'Improving student satisfaction in undergraduate construction management studies.' Proc., Australian Universities Building Education Association Annual Conference, July, 2006, Sydney.

Harvey, L. (2000). 'New realities: The relationship between higher education and employment.' Tertiary Education and Management, 6, 3-17.

Lingard, H. (2007). 'Conflict between paid work and study: does it impact upon students' burnout and satisfaction with university life?' Journal for Education in the Built Environment, 2, 90-109.

Lingard, H. (2005). 'Balancing study and paid work: the experiences of construction undergraduates in Australia.' Australian Journal of Construction Economics and Building, 5, 41-47.

Lingard, H., Mills, A. \& Ashford, P. (2003). 'Patterns of semester-time employment among undergraduate property and construction students: a preliminary investigation.' Proc., the Australasian University Building Educators Association 26th Annual conference, Geelong.

Knight, P. and M. York (2004). Learning curriculum and employability in higher education, Routledge Falmer, New York.

Kyles, D. (2006). 'Managing your multigenerational workforce.' Human Resource Management International Digest, 14(3), 53-55.

Litchfield, A., Frawley, J. and Nettleton, S. (2010). 'Contextualising and integrating into the curriculum the learning and teaching of work-ready professional graduate attributes.' Higher Education Research \& Development, 29, 519-534.

Litchfield, A. Nettleton, S. and Taylor, T. (2008). 'Integrating work-ready learning into the curriculum contextualised by profession.’ Proc., WACE ACEN Work Integrated Learning (WIL) conference: Transforming Futures, September 30 - October 3, Sydney.

Macquarie University. (2012). Curriculum Development, http://staff.mq.edu.au/teaching/curriculum_development/. viewed 27 Feb 2012

Mezirow, J. (1995). Fostering Critical Reflection in Adulthood - A Guide to Transformative and Emancipatory Learning, Jossey-Bass Publishers, San Francisco.

Newton, S. (2011). Learning and Teaching Academic Standards Project, Building and Construction, Final report, Australian Learning and Teaching Council, Sydney.

O’Shea, A. (2009). 'A developmental approach to work integrated learning.' Proc., Australian Collaborative Education Network conference (ACEN Queensland), October 1, Brisbane.

Orrell, J. (2004). 'Work integrated learning programmes: Management and educational quality.' Proc., Australian Universities Quality Forum proceedings, July 7-9, 2004, Adelaide, Australia, Australian Universities Quality Agency, pp 76-80.

Forsythe, P. (2012) 'Work integrated learning and the case for a "student-industry network" in undergraduate construction management programs', Australasian Journal of Construction Economics and Building, Conference Series, 12 (1) $1-11$ 
Pate, W. S. (1993). 'Consumer Satisfaction, Determinants, and Post-Purchase Actions in Higher Education: A Model to Guide Academic Managers.' College and University, 68,100-107.

Patrick, C., Peach, D. Pocknee, C. Webb, F. Fletcher, M. and Pretto, G (2008). The WIL (Work Integrated Learning) report: a national scoping study, Final Report, Queensland University of Technology.

Peach, D. and N. Gamble (2011). 'Scoping Work-Integrated Learning Purposes, Practices and Issues', in Developing Learning Professionals: Integrating Experiences in University and Practice Setting, eds. Billett, S. and Henderson, A., Springer, Netherlands, pp 169186.

Precision Consultancy (2007). Graduate employability skills: Prepared for the Business, Industry and Higher Education Collaborative Council, Canberra.

Sasser, A. (2009). Lasting connections: using internships to retain recent college graduates in New England, Policy Brief, New England Public Policy Center, Boston.

Scott, G. (2008). University student engagement and satisfaction with learning and teaching, Review of Australian Higher Education, DEEWR, Canberra.

Smith, M., Brooks, S., Lichtenberg, A., McIlveen, P., Torjul, P and Tyler, J. (2009). Career development learning: Maximising the contribution of work-integrated learning to the student experience, Final report, Australian Learning and Teaching Council, Wollongong.

Stinson, J. E. (1990). 'Integrated contextual learning: Situated learning in the business profession.' Proc., Annual Meeting of the American Educational Research Association, 16 -20 April, Boston, MA.

Universities Australia. (2008a). A National Internship Scheme - Enhancing the skills and work-readiness of Australian university graduates. Position Paper No. 3/08, retrieved from http://hdl.voced.edu.au/10707/1280, < February 27 2012>.

Universities Australia (2008b). Solutions for Building Australia's Human Capital through Universities, Canberra.

University of Technology Sydney. (2012). The UTS Model of Learning, retrieved from http://www.iml.uts.edu.au/curriculum/utsmodel.html, < February 27 2012>.

Forsythe, P. (2012) 'Work integrated learning and the case for a "student-industry network" in undergraduate construction management programs', Australasian Journal of Construction Economics and Building, Conference Series, 12 (1) $1-11$ 